\title{
Item-specific processing reduces false memories
}

\author{
DAVID P. MCCABE, ALISON G. PRESMANES, CHUCK L. ROBERTSON, and ANDERSON D. SMITH \\ Georgia Institute of Technology, Atlanta, Georgia
}

\begin{abstract}
We examined the effect of item-specific and relational encoding instructions on false recognition in two experiments in which the DRM paradigm was used (Deese, 1959; Roediger \& McDermott, 1995). Type of encoding (item-specific or relational) was manipulated between subjects in Experiment 1 and within subjects in Experiment 2. Decision-based explanations (e.g., the distinctiveness heuristic) predict reductions in false recognition in between-subjects designs, but not in within-subjects designs, because they are conceptualized as global shifts in decision criteria. Memory-based explanations predict reductions in false recognition in both designs, resulting from enhanced recollection of item-specific details. False recognition was reduced following item-specific encoding instructions in both experiments, favoring a memory-based explanation. These results suggest that providing unique cues for the retrieval of individual studied items results in enhanced discrimination between those studied items and critical lures. Conversely, enhancing the similarity of studied items results in poor discrimination among items within a particular list theme. These results are discussed in terms of the item-specific/ relational framework (Hunt \& McDaniel, 1993).
\end{abstract}

Interest in memory accuracy, particularly false memories, has increased in past years (Koriat, Goldsmith, \& Pansky, 2000). Part of this interest stems from novel findings with regard to how people remember that events did not occur in the past. That is, the way in which false alarms are avoided, and what factors influence this process, has become a focus of recent research. Because the Deese-Roediger-McDermott (DRM) false memory paradigm (Deese, 1959; Roediger \& McDermott, 1995) provides particularly robust false memories, it has been particularly useful in examining these questions. In the DRM paradigm, participants study lists of words that are associates of nonpresented words, called critical lures. Recognition tests often reveal false alarm rates for critical lures that are comparable to the hit rates for studied words. Although it is nearly impossible to eliminate this effect entirely, research suggests that distinctive processing of studied items reduces false memories (see Arndt \& Reder, 2003 , for a brief review). However, there is some debate as to whether these reductions are the result of memorybased factors (Arndt \& Reder, 2003; Smith \& Hunt, 1998) or decision processes (Dodson \& Schacter, 2001; Schacter, Israel, \& Racine, 1999). The present experiments tested the hypothesis that item-specific processing leads

This research was supported by a grant from the National Institute on Aging. We thank Robert Nosofsky, Marilyn Smith, and two anonymous reviewers for comments on previous versions of this article. We also thank Lisa Geraci for helpful suggestions. A.G.P. is now at Vanderbilt University. C.L.R. is now at North Georgia State College and State University. These experiments were conducted as part of a larger study that was completed as the first author's doctoral dissertation. Correspondence concerning this article should be addressed to D. P. McCabe, Department of Psychology, Washington University, St. Louis, MO 631304899 (e-mail: dmccab@artsci.wustl.edu). to reductions of false recognition (Arndt \& Reder, 2003; Smith \& Hunt, 1998) and supported the notion that, in some cases, decision processes play a secondary role in false recognition reduction.

The general approach used to determine whether reductions of false recognition are the result of memorybased or decision-based factors is to compare the patterns of false recognition across between-subjects and within-subjects designs. An example of this approach with respect to isolating decision processes illustrates its usefulness. Dodson and Schacter (2001) reported evidence in favor of a decision-based reduction of false recognition that they call the distinctiveness heuristic. They compared false recognition in conditions in which participants heard studied words or read them out loud (both groups saw the words presented on the computer screen). False recognition was lower in the group that read the words aloud than in the group that only heard the words. However, this result was not obtained in a within-subjects design (Experiment 2) in which half of the DRM lists were heard and half were read aloud. In this case, there was no difference in false recognition of critical lures associated with the heard lists versus the read-aloud lists. Dodson and Schacter (2001) argued that reading the words aloud in the between-subjects design encouraged the participants to reduce false recognition by changing their decision criteria ${ }^{1}$ (i.e., the type or amount of information used to make recognition decisions), so that they demanded access to auditory details before accepting an item as old. According to the distinctiveness heuristic, participants develop a metamemorial belief such that they expect to remember particular types of information from the study episode (i.e., auditory details), which in turn causes them to adopt decision criteria consistent with these beliefs. In the example above, the par- 
ticipants become more likely to base their responses on auditory information after reading words aloud. False recognition was not reduced for read-aloud lists when only a subset of studied words were said aloud (i.e., in the within-subjects design), because the distinctiveness heuristic is applied globally to all of the items on the recognition test (Schacter et al., 1999). Other support for this sort of global change in decision criteria in the DRM paradigm comes from experiments in which false recognition is reduced when participants study pictures, as compared with words, in between-subjects designs, but false recognition does not differ between picture and word conditions in within-subjects designs (Schacter, Cendan, Dodson, \& Clifford, 2001; Schacter et al., 1999). Other memory research supports the notion that decision criteria do not change on recognition tests on an itemby-item basis as well, even when participants are encouraged to change their criteria in this way. For example, Stretch and Wixted (1998) had participants study words in a red or green font, with the red words presented once and the green words presented five times. Despite dramatic differences in the memorability of these two types of items, the rejection rate for new words that were red or green did not differ. This suggests that the participants judged whether test items were old or new on the basis of the same types of information, even when given an alternative, more effective basis on which to reject them.

In contrast to decision-based explanations, memorybased explanations suggest that increasing the distinctiveness of studied items leads directly to reductions in false memories (Arndt \& Reder, 2003; Smith \& Hunt, 1998). Specifically, engaging in item-specific processing allows participants to reject critical lures because critical lures lack the item-specific details that studied items possess. Theoretically, the framework of Hunt and colleagues (Hunt \& McDaniel, 1993; Smith \& Hunt, 1998) provides a straightforward explanation of why item-specific processing is likely to reduce false remembering. Item-specific processing focuses attention on aspects of individual items that differentiate each item from others within an event, thereby making those items distinct with respect to one another. According to this framework, focusing attention on differences in the context of similarity results in distinctive processing. In the case of the DRM paradigm, this distinctive processing allows individual studied items to be differentiated from one another on the recognition test, and as a byproduct of this discrimination, critical lures are rejected. We should note, too, that any reduction of false recognition requires the involvement of decision processes, but memory-based reductions requires that participants engage in item-specific processing at the time of study, whereas decision-based reductions result from a metamemorial belief that items should be well remembered in a given context and are not predicated on differences in the how memorable the studied items are per se. Importantly, the memory-based explanation predicts that critical lures associated with distinct studied items will be rejected regardless of whether a between- or a withinsubjects design is used.

Arndt and Reder (2003) compared within-subjects versus between-subjects designs to examine whether item-specific perceptual processing would reduce false memories. They compared conditions in which studied items were made perceptually distinct or nondistinct during study. The distinctive condition involved presenting each word associated with a particular DRM list in a unique (i.e., distinct) font. In the nondistinct condition, they presented all of the words associated with a particular DRM list in the same (i.e., nondistinct) font. In the distinctive font condition, false memories were reduced whether distinctiveness was manipulated between subjects or within subjects. Because the reductions of false memories occurred in the within-subjects as well as in the between-subjects condition, the reduced rates of false recognition could not have been the result of a global change in decision criteria. Other researchers have reported similar results with within-subjects designs (Gallo, McDermott, Percer, \& Roediger, 2001).

One important aspect of all the previous experiments in which false recognition across within- vs. betweensubjects designs has been compared is that all of the item-specific manipulations have involved enhancing the perceptual features of studied stimuli. For example, the distinctiveness heuristic has been shown for pictures versus words (Dodson \& Schacter, 2002; Schacter et al., 1999) and for the saying of words versus the hearing of words (Dodson \& Schacter, 2001). Item-specific processing manipulations involve presenting items in different fonts (Arndt \& Reder, 2003) or comparing visual with auditory study (Gallo et al., 2001). Although the term item specific is often used to refer specifically to the perceptual features of stimuli (Mandler, 1980), the item-specific/relational framework of Hunt and colleagues (Hunt \& McDaniel, 1993; Smith \& Hunt, 1998) is more general in its use of the term item specific, referring to the cognitive consequences of processing differences in the context of similarity. Thus, according to Hunt and colleagues, the use of perceptually distinct stimuli should not be necessary to show an item-specific processing advantage in memory. We tested this assumption of their framework by holding stimulus conditions constant and manipulating the encoding instructions given to participants across conditions.

\section{EXPERIMENT 1}

We will report two experiments in which the predictions of the item-specific/relational framework of Hunt and colleagues were examined directly using encoding instructions designed to enhance one or the other type of processing. In both the experiments, the participants studied ten 10-word DRM lists, followed by a recognition test. In Experiment 1, we compared relational and item-specific encoding instructions in a between-subjects design. Experiment 2 was a replica of Experiment 1 with a within-subjects design in which half of the lists were 
studied using a relational encoding strategy and the other half using an item-specific strategy. For the item-specific encoding strategy, we asked the participants to think of a unique characteristic of each studied word that differentiated that word from other studied words in a DRM list. This encoding strategy was expected to allow later discrimination between items within each DRM list by making each item more distinct. By contrast, for the relational encoding strategy, we asked the participants to focus explicitly on the similarities among the studied words in each 10-word DRM list and to try to relate the words to one another. This type of processing is redundant with list structure (i.e., the thematic relation among the words) and is the default encoding strategy used under standard intentional learning instructions with related word lists (Hunt \& McDaniel, 1993). This should result in the high rates of false recognition that are typically observed (McCabe \& Smith, 2002; Roediger \& McDermott, 1995).

\section{Method}

Participants. Forty-eight participants took part in the experiment for course credit at the Georgia Institute of Technology.

Materials and Procedure. Two sets of ten 10-word DRM lists were used (Stadler, Roediger, \& McDermott, 1999, norms). Set 1 included studied words corresponding to the critical lures window, sleep, sweet, slow, smell, soft, chair, doctor, river, and rubber. Set 2 included studied words corresponding to the critical lures cup, rough, smoke, high, needle, cold, trash, thief, mountain, and music. Each set was presented in the same random order for every participant. The first 10 words from each list were used, and they were ordered from highest to lowest forward associative strength. Each set was equated for the probability of eliciting false recognition from the norms. The set that was not presented at study provided distractors for the recognition test. Each 10-word DRM list was separated by a camera click sound and a 2 -sec delay. For each 10 -word list, words from Serial Positions 1, 4, and 8 (studied targets), as well as the critical lure corresponding to the list, were included on the recognition test. Targets from the nonstudied lists are called control targets, and critical lures associated with those words are called control lures. Test items were presented visually, one at a time, on the computer screen, and the participants responded on the recognition test by pressing keys marked "SN," "PN," "PO," or "SO" on the number pad. These keys corresponded to the responses sure new, probably new, probably old, and sure old, respectively. These response options were displayed on the screen as well, in a box below each test item. The order of test items was randomized for every participant.

Half of the participants were given instructions verbally from the experimenter explaining how to use the relational strategy. The other half were given instructions explaining how to use the itemspecific strategy. The relational group was asked to relate the words in each 10-word DRM list to one another and to concentrate on what the words had in common, in order to associate them with one another. The item-specific instructions asked the participants to think of one unique characteristic for each word that differentiated it from other words in the list. An example list, corresponding to the critical lure shirt, was presented to give the participants practice studying using the instructed strategy. Any questions about the strategy were answered at that time. Examples of each type of processing were given before the practice list.

Studied words were presented at a rate of one word every $4 \mathrm{sec}$. The recognition test followed immediately after all 10 lists had been studied. The participants pressed one of the four keys marked on the keyboard to respond for each test item, indicating whether the test item was old or new and how confident they were in this response (sure or probably). They were instructed that there was no time limit and that they should be as accurate as possible.

\section{Results}

The results are presented in Table 1 . Recognition results were analyzed as proportion called old, collapsed across confidence ratings. The significance level was set at $p<.05$ for all the statistical tests. There were four types of test items on the recognition test: studied targets, critical lures, control targets, and control lures. The control items were the items from the unstudied set. Corrected veridical recognition $(\mathrm{Pr})$ was calculated by subtracting the false alarm rate for the control targets from the hit rate for the studied targets (Snodgrass \& Corwin, 1988). Corrected false recognition (Pr) was computed by subtracting false alarms for the control lures from that for the critical lures. These data are presented in the first two rows of Table 1, on the left-hand side. The raw scores (i.e., proportion called old) are presented in rows 5-8.

A 2 (encoding group: item specific or relational) $\times 2$ (memory type: veridical $\mathrm{Pr}$ or false $\mathrm{Pr}$ ) mixed model analysis of variance (ANOVA) was conducted, with encoding group as a between-group variable, and memory type as a repeated measures variable. There were signif-

Table 1

Veridical and False Recognition Measures for Between-Subjects (Experiment 1) and WithinSubjects (Experiment 2) Designs for Each Encoding Condition (i.e., Item-Specific vs. Relational)

\begin{tabular}{|c|c|c|c|c|c|c|c|c|}
\hline \multirow[b]{3}{*}{ Recognition Measure } & \multicolumn{4}{|c|}{ Experiment 1 (Between-Subjects) } & \multicolumn{4}{|c|}{ Experiment 2 (Within-Subjects) } \\
\hline & \multicolumn{2}{|c|}{ Item-Specific } & \multicolumn{2}{|c|}{ Relational } & \multicolumn{2}{|c|}{ Item-Specific } & \multicolumn{2}{|c|}{ Relational } \\
\hline & $M$ & $S D$ & $M$ & $S D$ & $M$ & $S D$ & $M$ & $S D$ \\
\hline Corrected veridical $(\mathrm{Pr})$ & .71 & .12 & .71 & .15 & .76 & .21 & .76 & .17 \\
\hline Corrected false $(P r)$ & .42 & .20 & .63 & .19 & .40 & .31 & .54 & .26 \\
\hline Veridical bias $(B r)$ & .49 & .20 & .47 & .19 & .45 & .28 & .40 & .23 \\
\hline False bias $(B r)$ & .41 & .26 & .53 & .21 & .32 & .25 & .40 & .24 \\
\hline Studied targets & .86 & .07 & .85 & .08 & .88 & .13 & .87 & .09 \\
\hline Control targets & .15 & .09 & .14 & .11 & .12 & .15 & .12 & .15 \\
\hline Critical lures & .64 & .24 & .84 & .11 & .58 & .28 & .73 & .21 \\
\hline Control lures & .22 & .15 & .21 & .15 & .19 & .19 & .19 & .19 \\
\hline
\end{tabular}


icant main effects of encoding group $[F(1,46)=10.22$, $\left.M S_{\mathrm{e}}=0.24\right]$ and memory type $\left[F(1,46)=25.17, M S_{\mathrm{e}}=\right.$ $0.81]$ and a significant interaction as well $[F(1,46)=$ $\left.7.98, M S_{\mathrm{e}}=0.26\right]$. Planned comparisons revealed no differences between the processing groups for veridical $\mathrm{Pr}$ $\left[F(1,46)=0.009, M S_{\mathrm{e}}=0.000001\right]$, but false $\operatorname{Pr}$ was lower in the item-specific group than in the relational group $\left[F(1,46)=13.31, M S_{\mathrm{e}}=0.49\right]$. This confirms the hypothesis that item-specific encoding leads to less false remembering than does relational encoding.

We examined decision bias by conducting a mixed model ANOVA with encoding group as a between-subjects variable and memory type (veridical $\mathrm{Br}$ or false $\mathrm{Br}$ ) as a within-subjects factor. Response bias $(\mathrm{Br})$ was measured using the formulas in Snodgrass and Corwin ${ }^{2}$ (1988). For $B r$, values of .5 indicate a neutral response bias, with values greater than .5 indicating liberal responding, and values below .5 indicating more conservative responding. These data are presented in Rows 3 and 4 of Table 1. There were no significant effects of encoding group $\left[F(1,46)=1.25, M S_{\mathrm{e}}=0.07\right]$ or memory type $[F(1,46)=$ $\left.0.08, M S_{\mathrm{e}}=0.003\right]$ and no significant interaction between the two variables $\left[F(1,46)=3.40, M S_{\mathrm{e}}=0.13\right]$. Planned comparisons revealed no differences between the encoding groups in veridical $\operatorname{Br}[F(1,46)=0.11$, $\left.M S_{\mathrm{e}}=0.004\right]$. False $\mathrm{Br}$ was greater in the relational group than in the item-specific group, indicating more liberal responding in the relational group, although this finding failed to reach conventional levels of significance $\left[F(1,46)=9.17, M S_{\mathrm{e}}=0.44, p=.072 .09\right]$. We should point out that this near-significant difference in response bias, indicating more liberal responding in the relational group, is driven by higher rates of false alarms to the critical lures in the relational condition, rather than by differences in false alarm rates for unrelated distractors between the instruction groups. The fact that the false alarm rates for unrelated distractors are nearly identical across conditions rules out explanations for our results based on group or condition differences in criterion shifts (cf. Miller \& Wolford, 1999).

\section{EXPERIMENT 2}

Experiment 1 confirmed that item-specific encoding results in less false recognition than does relational encoding. Finding this pattern of results with a between-subjects design is consistent with both memory-based and decisionbased explanations of false recognition reduction. In Experiment 2, a within-subjects design was employed in an effort to differentiate these two explanations.

\section{Method}

Participants. Thirty-two participants took part for course credit at the Georgia Institute of Technology.

Materials and Procedure. Experiment 2 was identical to Experiment 1 , with the exception that half (five) of the 10-word lists presented to a given participant were rehearsed using the relational strategy and half (five) were studied using the item-specific strategy. The type of encoding alternated for every 10 -word list, and the order was counterbalanced across participants. The experimenter stated which type of encoding should be performed immediately before each list began.

\section{Results}

The results are presented in Table 1. A 2 (encoding group: item-specific or relational) $\times 2$ (memory type: veridical $\mathrm{Pr}$ or false $\mathrm{Pr}$ ) repeated measures ANOVA was conducted. There were significant main effects of encoding group $\left[F(1,31)=7.82, M S_{\mathrm{e}}=0.15\right]$ and memory type $\left[F(1,31)=42.84, M S_{\mathrm{e}}=2.73\right]$ and a significant interaction as well $\left[F(1,31)=9.93, M S_{\mathrm{e}}=0.17\right]$. Planned comparisons revealed no differences between the encoding groups for veridical $\operatorname{Pr}\left[F(1,31)=0.05, M S_{\mathrm{e}}=0.003\right]$, but false $P r$ was lower in the item-specific group than in the relational group $\left[F(1,31)=10.46, M S_{\mathrm{e}}=0.32\right]$. This finding in a within-subjects design again confirms the hypothesis that item-specific encoding leads to less false remembering than does relational encoding and suggests that this results from item-specific discrimination, rather than as the result of decision processes alone.

We examined decision bias by conducting a 2 (encoding group: item-specific or relational) $\times 2$ (memory type: veridical $\mathrm{Br}$ or false $\mathrm{Br}$ ) repeated measures ANOVA. There was no main effect of encoding group $[F(1,46)=0.34$, $\left.M S_{\mathrm{e}}=0.006\right]$, but there was a difference between memory measures $\left[F(1,46)=4.45, M S_{\mathrm{e}}=0.14\right]$ and a significant interaction between the two variables $[F(1,46)=10.37$, $\left.M S_{\mathrm{e}}=0.13\right]$. Planned comparisons revealed no significant difference between the encoding groups in veridical $\mathrm{Br}$ $\left[F(1,46)=2.16, M S_{\mathrm{e}}=0.04\right]$, but false $B r$ was more liberal in the relational group than in the item-specific group $\left[F(1,46)=7.23, M S_{\mathrm{e}}=0.09\right]$. Again, this difference in response bias is driven by higher rates of false alarms to the critical lures in the relational condition, but false alarms to unrelated distractors did not differ.

\section{GENERAL DISCUSSION}

In two experiments, false recognition of critical lures was reduced for participants who focused on the unique attributes of each studied item, as compared with participants who focused on the similarity of studied items. This result occurred whether these variables were manipulated between subjects (Experiment 1) or within subjects (Experiment 2). Finding a differential reduction of false recognition for critical lures associated with lists that were studied with item-specific processing instructions favors a memory-based explanation and effectively rules out a global change in decision criteria as the primary cause of these reductions.

There are important similarities and differences in memory-based and decision-based explanations of false recognition reduction. Both explanations suggest that distinctiveness encourages participants to reduce or suppress false recognition. However, the memory-based explanation of false recognition reduction focuses on differences in the fidelity of the representation of studied 
items in memory, whereas the decision-based explanation suggests that differences in the belief about what should be remembered cause reduced rates of false recognition. Some might argue that veridical recognition should have been enhanced for the item-specific encoding condition if there was enhancement of memory for the studied words. However, relational encoding instructions actually enhance memory for the type of information needed to be effective at veridical recognition, so this result is not entirely surprising. That is, because relational processing enhances memory for the theme or gist of each studied list and veridical recognition can be accurate on the recognition test by responding old to any test items consistent with the gist or theme of studied lists, veridical recognition was excellent for the relational processing conditions. However, the participants in the relational conditions were not able to discriminate between studied items and critical lures, because this requires item-specific discrimination. Hunt (2003) recently provided similar evidence indicating that relational processing can enhance veridical recognition but does so at the expense of increased false recognition, whereas item-specific processing increased veridical recognition and decreased false recognition. Another way to think of this result is that the veridical recognition measure is similar to the inclusion condition in a process dissociation experiment (Jacoby, 1991). That is, participants can be accurate in veridical recognition by recollecting the item-specific attributes of studied items or by simply responding old to familiar test items and new to unfamiliar test items. However, for the false recognition measure, only recollection of item-specific attributes allows participants to effectively reject critical lures. Thus, the veridical recognition measure used in the present experiments and in most typical DRM experiments simply is not a very good measure of item-specific processing.

We should note that although we have contrasted memory-based and decision-based explanations of false recognition reduction, we believe decision criteria to be important in any reduction of false recognition. However, we disagree with the assertion that shifts in decision criteria alone are the primary means by which false memories are reduced in this paradigm (Dodson \& Schacter, 2001). Memory-based processes also play a prominent and potent role in the reduction of false memories. We note, too, that these two types of false recognition reduction are not necessarily mutually exclusive, and could potentially be used concurrently to reduce false memories (McCabe, 2003).

The more important question for the present discussion is how the two proposed mechanisms differ in terms of the particular processes that are involved in their implementation. Experiments showing reductions in false recognition as the result of memory-based processes (e.g., Arndt \& Reder, 2003; Smith \& Hunt, 1998) have instructed participants to focus attention on item-specific attributes, which likely causes these attributes to become the primary means by which similar items are discrimi- nated on a later recognition test. Thus, in the item-specific encoding condition, instructing the participants to generate unique cues for studied words likely encouraged retrieval of those cues to aid the verification process (i.e., "Is this item old, or is it familiar but new?"), resulting in a rejection of the critical lures. This is consistent with the notion that retrieval monitorig allows reductions of false recognition following item-specific processing.

Our data also indicate that item-specific reductions of false memories can be achieved using a nonperceptual manipulation of distinctiveness. Hunt (1995) has pointed out that there is often confusion with respect to how the term distinctiveness is used. It can be used to refer to an independent variable (e.g., pictures are more distinctive than words) and to a theoretical explanation for the effect of an independent variable (e.g., pictures were better remembered because they were distinctive). This raises problems, because the reasoning involved in using distinctiveness both as an independent variable and as an explanation for the effect of that variable is circular. In the item-specific/relational framework (Hunt \& McDaniel, 1993), distinctiveness is used to refer to a psychological interpretation of the cognitive processing engaged in by the participant, rather than as some inherent property of the stimuli that are manipulated. Thus, our use of a rehearsal manipulation to investigate the effects of item-specific distinctiveness is important because it clarifies that it is, in fact, the processing, and not the stimuli, that are important to item-specific reductions of false memories. Admittedly, manipulations of perceptual item-specific processing (Arndt \& Reder, 2003; Smith $\&$ Hunt, 1998) have been effective in reducing false memories, but our experiments go beyond these previous investigations in clarifying the theoretical mechanism responsible for the effect.

Classifying distinctiveness manipulations as perceptual or nonperceptual is important for other reasons as well. For example, recent work by Koutstaal and colleagues (Koutstaal, 2003; Koutstaal et al., 2003) indicates that older adults may have a specific deficit in using itemspecific perceptual processing to reduce false memories, as compared with young adults, but other work indicates that older adults can use nonperceptual item-specific processing to reduce false recognition (McCabe, 2003). Similar results have been reported in the source-monitoring literature as well, with age-related source-monitoring deficits occurring when participants are asked to make source judgments on perceptual dimensions, but not when they make discriminations by using nonperceptual attributes of sources (Rahhal, May, \& Hasher, 2002).

Finally, we should note that simply enhancing the memorability of studied words is not enough to reduce false memories and may actually increase the proportion of false memories under some circumstances. For example, deeper (semantic) levels of processing and blocking lists according to theme (as opposed to randomly presenting them) increases both veridical and false memories (Toglia, Neuschatz, \& Goodwin, 1999). Toglia et al. referred to 
this effect as a more is less effect, because more veridical memory leads to less accuracy in memory. Our results suggest that item-specific encoding leads to a more is more effect, with more item-specific processing leading to more accurate memory.

\section{REFERENCES}

ARndt, J., \& Reder, L. M. (2003). The effect of distinctive visual information on false recognition. Journal of Memory \& Language, $\mathbf{4 8}$, $1-15$.

DEESE, J. (1959). On the prediction of occurrence of particular verbal intrusions in immediate recall. Journal of Experimental Psychology, 58, 17-22.

DODSON, C. S., \& SCHACTER, D. L. (2001). "If I had said it I would have remembered it": Reducing false memories with a distinctiveness heuristic. Psychonomic Bulletin \& Review, 8, 155-161.

Dodson, C. S., \& SchaCTER, D. L. (2002). When false recognition meets metacognition: The distinctiveness heuristic. Journal of Memory \& Language, 46, 782-803.

Gallo, D. A., McDermott, K. B., Percer, J. M., \& Roediger, H. L., III (2001). Modality effects in false recall and false recognition. Journal of Experimental Psychology: Learning, Memory, \& Cognition, 27, 339-353.

HuNT, R. R. (1995). The subtlety of distinctiveness: What von Restorff really did. Psychonomic Bulletin \& Review, 2, 105-112.

Hunt, R. R. (2003). Two contributions of distinctive processing to accurate memory. Journal of Memory \& Language, 48, 811-825.

Hunt, R. R., \& McDaniel, M. A. (1993). The enigma of organization and distinctiveness. Journal of Memory \& Language, 32, 421-445.

JACOBY, L. L. (1991). A process dissociation framework: Separating automatic from intentional uses of memory. Journal of Memory \& Language, 30, 513-541.

Johnson, M. K., Hashtroudi, S., \& Lindsay, D. S. (1993). Source monitoring. Psychological Bulletin, 114, 3-28.

Koriat, A., Goldsmith, M., \& PANSKY, A. (2000). Toward a psychology of memory accuracy. Annual Review of Psychology, 51, 481-537.

KoutstaAl, W. (2003). Older adults encode - but do not use-perceptual details: Intentional versus unintentional effects of detail on memory judgments. Psychological Science, 14, 189-193.

Koutstaal, W., Reddy, C., Jackson, E. M., Prince, S., Cendan, D. L., \& Schacter, D. L. (2003). False recognition of abstract versus common objects in older and younger adults: Testing the semantic categorization account. Journal of Experimental Psychology: Learning, Memory, \& Cognition, 29, 499-510.

MANDLER, G. (1980). Recognizing: The judgment of previous occurrence. Psychological Review, 87, 252-271.

McCABE, D. P. (2003). Decision-based and memory-based reductions of false recognition in young and older adults. Unpublished doctoral dissertation. Georgia Institute of Technology.

McCABE, D. P., \& SMith, A. D. (2002). The effect of warnings on false memories in young and older adults. Memory \& Cognition, 30, 10651077.

Miller, M. B., \& Wolford, G. L. (1999). Theoretical commentary: The role of criterion shift in false memory. Psychological Review, 106, 398-405.

RAHHAL, T. A., MAY, C. P., \& HASHER, L. (2002). Truth and character: Source that older adults can remember. Psychological Science, 13, 101-105.

Roediger, H. L., III, \& McDermott, K. B. (1995). Creating false memories: Remembering words not presented in lists. Journal of Experimental Psychology: Learning, Memory, \& Cognition, 21, 803814.

Schacter, D. L., Cendan, D. L., Dodson, C. S., \& Clifford, E. R. (2001). Retrieval conditions and false recognition: Testing the distinctiveness heuristic. Psychonomic Bulletin \& Review, 8, 827-833.

Schacter, D. L., Israel, L., \& Racine, C. (1999). Suppressing false recognition in younger and older adults: The distinctiveness heuristic. Journal of Memory \& Language, 40, 1-24.

Smith, R. E., \& Hunt, R. R. (1998). Presentation modality affects false memory. Psychonomic Bulletin \& Review, 5, 710-715.

Snodgrass, J. G., \& CorwIN, J. (1988). Pragmatics of measuring recognition memory: Applications to dementia and amnesia. Journal of Experimental Psychology: General, 117, 34-50.

Stadler, M. A., Roediger, H. L., III, \& MCDermott, K. B. (1999). Norms for word lists that create false memories. Memory \& Cognition, 27, 494-500.

STRETCH, V., \& WIXTED, J. T. (1998). On the difference between strengthbased and frequency-based mirror effects in recognition memory. Journal of Experimental Psychology: Learning, Memory, \& Cognition, 24, 1379-1396.

ToGLia, M. P., Neuschatz, J. S., \& Goodwin, K. A. (1999). Recall accuracy and illusory memories: When more is less. Memory, 7, 233-256.

\section{NOTES}

1. We should note that the use of the term decision criteria as the type or amount of information used in a recognition decision is consistent with Johnson's source-monitoring framework (Johnson, Hashtroudi, \& Lindsay, 1993) and should not be confused with response bias, or response criteria, which refers to the threshold used by observers in a signal detection model. Response bias can be conceptualized as how liberal or conservative a participant is on a unidimensional decision axis, whereas decision criteria refers to the type or amount of information used in a recognition decision (e.g., a participant basing his or her recognition response on retrieval of semantic information or retrieval of perceptual information).

2. Response bias was calculated as false alarms/[false alarms (hits - false alarms)], taken from Snodgrass and Corwin (1988).

(Manuscript received September 15, 2003; revision accepted for publication January 20, 2004.) 